\title{
A Nonsense Mutation of the Sodium Channel Gene SCN2A in a Patient with Intractable Epilepsy and Mental Decline
}

\author{
Kazusaku Kamiya, ${ }^{1}$ Makoto Kaneda, ${ }^{2}$ Takashi Sugawara, ${ }^{1}$ Emi Mazaki, ${ }^{1}$ Nami Okamura, ${ }^{1}$ Mauricio Montal, ${ }^{3}$ \\ Naomasa Makita, ${ }^{4}$ Masaki Tanaka, ${ }^{5}$ Katsuyuki Fukushima, ${ }^{5}$ Tateki Fujiwara, ${ }^{5}$ Yushi Inoue, ${ }^{5}$ and Kazuhiro Yamakawa ${ }^{1}$ \\ ${ }^{1}$ Laboratory for Neurogenetics, RIKEN Brain Science Institute, Saitama 351-0198, Japan, ${ }^{2}$ Department of Physiology, Keio University School of Medicine, \\ Tokyo 160-8582, Japan, ${ }^{3}$ Section of Neurobiology, Division of Biological Sciences, University of California, San Diego, La Jolla, California 92093 , \\ ${ }^{4}$ Department of Cardiovascular Medicine, Hokkaido University Graduate School of Medicine, Sapporo 060-8638, Japan, and ${ }^{5}$ National Epilepsy Center, \\ Shizuoka Medical Institute of Neurological Disorders, Shizuoka 420-8688, Japan
}

Mutations, exclusively missense, of voltage-gated sodium channel $\alpha$ subunit type 1 (SCN1A) and type 2 (SCN2A) genes were reported in patients with idiopathic epilepsy: generalized epilepsy with febrile seizures plus. Nonsense and frameshift mutations of SCN1A, by contrast, were identified in intractable epilepsy: severe myoclonic epilepsy in infancy (SMEI). Here we describe a first nonsense mutation of $S C N 2 A$ in a patient with intractable epilepsy and severe mental decline. The phenotype is similar to SMEI but distinct because of partial epilepsy, delayed onset (1 year 7 months), and absence of temperature sensitivity. A mutational analysis revealed that the patient had a heterozygous de novo nonsense mutation $\mathrm{R} 102 \mathrm{X}$ of $S C N 2 A$. Patch-clamp analysis of $\mathrm{Na}_{\mathrm{v}} 1.2$ wild-type channels and the R102X mutant protein coexpressed in human embryonic kidney 293 cells showed that the truncated mutant protein shifted the voltage dependence of inactivation of wild-type channels in the hyperpolarizing direction. Analysis of the subcellular localization of R102X truncated protein suggested that its dominant negative effect could arise from direct or indirect cytoskeletal interactions of the mutant protein. Haploinsufficiency of $\mathrm{Na}_{\mathrm{v}} 1.2$ protein is one plausible explanation for the pathology of this patient; however, our biophysical findings suggest that the R102X truncated protein exerts a dominant negative effect leading to the patient's intractable epilepsy.

Key words: SCN2A; sodium channel; nonsense mutation; epilepsy; mental decline; dominant negative

\section{Introduction}

Mutations of voltage-gated sodium channel (VGSC) genes are known to be responsible for human epilepsy. Initially, a heterozygous missense mutation of VGSC $\beta 1$ accessory subunit gene (SCN1B) on chromosome 19q13.1 was identified in patients with generalized epilepsy with febrile seizures plus (GEFS+; Wallace et al., 1998). Subsequently, a second locus was reported on 2q13q31 (Baulac et al., 1999; Moulard et al., 1999), and heterozygous missense mutations of VGSC $\alpha$-subunit type 1 gene (SCN1A) on 2 q24 were identified in families with GEFS + (Escayg et al., 2000). Subsequent reports of SCN1A mutations have further implicated SCN1A dysfunction in GEFS + (Escayg et al., 2001; Sugawara et al., 2001a; Wallace et al., 2001b). Moreover, SCN1A mutations were also described in patients with severe myoclonic epilepsy in infancy (SMEI; Claes et al., 2001; Sugawara et al., 2002).

GEFS + is a clinical subset of febrile seizures, and patients show variable seizure types, including absence, myoclonic, tonicclonic, and partial seizures (Scheffer and Berkovic, 1997; Ito et al.,

Received June 26, 2003; revised Jan. 19, 2004; accepted Jan. 19, 2004.

This work was supported in part by a grant from RIKEN Brain Science Institute. Research at the University of California was supported by National Institutes of Health Grant GM-49711. We thank Prof. Akimichi Kaneko (Department of Physiology, Keio University School of Medicine) for letting us to use the facilities.

Correspondence should be addressed to Dr. Kazuhiro Yamakawa, Laboratory for Neurogenetics, RIKEN Brain Science Institute, 2-1 Hirosawa, Wako-shi, Saitama 351-0198, Japan. E-mail: yamakawa@brain.riken.go.jp.

DOI:10.1523/JNEUROSCI.3089-03.2004

Copyright $\odot 2004$ Society for Neuroscience $\quad$ 0270-6474/04/242690-09\$15.00/0
2002). Antiepileptic drugs mostly work, and seizures stop spontaneously in some cases. By contrast, SMEI is very severe epilepsy (Dravet, 1978). In the first year of life, patients manifest frequent and fever-sensitive refractory clonic, tonic-clonic seizures, accompanied later by additional seizures, including myoclonic, absence, or complex partial seizures. Severe deterioration of psychomotor development is observed in most cases (Dravet et al., 1982, 1992).

Intriguingly, GEFS + mutations of SCN1A are exclusively missense, whereas most $(\sim 70 \%)$ SMEI mutations are truncation type such as nonsense and frameshift (Fujiwara et al., 2003). Biophysical analysis of GEFS+ mutations of SCN1B and SCN1A showed that those mutations increase $\mathrm{Na}^{+}$currents (Wallace et al., 1998; Lossin et al., 2002). Recently, we reported that the SMEI mutations of SCN1A, not only nonsense but also missense mutations, showed attenuated $\mathrm{Na}^{+}$currents (Sugawara et al., 2003).

For the VGSC type 2 gene (SCN2A) encoding the $\mathrm{Na}_{\mathrm{v}} 1.2$ channel, we previously reported a first missense mutation in a patient with febrile and afebrile seizures that is similar to GEFS+ (Sugawara et al., 2001b). Biophysical analysis revealed that the $\mathrm{Na}_{\mathrm{v}} 1.2$ mutant channel inactivated more slowly, suggesting an increase of sodium ion influx. Recently, two missense mutations of SCN2A were documented in patients with benign familial neonatal-infantile seizures, a type of epilepsy that is even milder than GEFS + (Heron et al., 2002). In contrast to a number of nonsense and frameshift mutations of SCN1A reported in SMEI, no 
SCN2A truncation mutation has been described in patients with any type of epilepsy.

In this study, we describe a first nonsense mutation of $S C N 2 A$ in a patient with intractable childhood epilepsy associated with severe mental decline; the phenotype is similar yet distinct to SMEI. We also demonstrate that the truncated protein has a dominant negative effect on the wild-type $\mathrm{Na}_{\mathrm{v}} 1.2$ channel, and it could be mediated by direct or indirect cytoskeletal interactions. The dominant negative effect of the mutant protein appears to be the major functional consequence of this genetic defect, which may possibly explain the molecular pathology of this severe epilepsy.

\section{Materials and Methods Patients}

This study recruited 60 unrelated Japanese patients clinically diagnosed with intractable childhood epilepsies, including SMEI. The informed consents were obtained from the parents or responsible adults when necessary, and these were approved by the Ethical Committees of Shizuoka Medical Institute of Neurological Disorders and the Institutional Review Board of RIKEN Brain Science Institute.

The patient with the SCN2A nonsense mutation is 29 -year-old female. Her mother had several febrile convulsions until 6 years of age. Her father is phenotypically normal and had no history of seizure. The paternity was confirmed by using highly polymorphic markers distributed on chromosomes. This patient had no relevant personal history, and the psychomotor development was unremarkable until the age of 2 years, when she became hyperkinetic and autistic. Seizures appeared at age 1 year 7 months. She fell down abruptly forward several times a day. She began to take phenobarbital, and the seizures soon disappeared. The medication was discontinued at age 4 years 5 months. The EEG was reported to show only slow waves initially, but after 3 years, spike activity appeared and increased. At age 6 years, convulsive seizures began to occur mainly during sleep and repeated 1-2 times weekly, often in clusters. The seizures were preceded by versive movement of the head toward the left or by clonic movement of the left upper extremity. The medication was restarted. However, when the dose of medication was increased, she began to show recurrent brief episodes with apathetic expression (absence-like seizure) and brief atonia of the hands, resulting in falling off things she had in her hand. At that time, the EEG showed frequent bilateral sharp waves or spike waves with maximum amplitude over the centroparietotemporal region (semicontinuous during sleep). When admitted to the hospital at age 10 years, atonia of the upper extremities was frequently observed in concomitance with the spike wave discharges in the EEG. The head nodded forward, and she dropped her hand. These atonic movements disappeared when polypharmacy (five drugs including carbamazepine) was simplified to valproate monotherapy. The EEG then mostly improved: bilateral discharges disappeared and only sharp waves in the centroparietotemporal region on the right side were observed. However, the convulsive seizures that proved to be partial onset by ictal EEG recording (see Fig. 2) were difficult to treat despite various medication trials, and she still had weekly convulsions. Any factors of seizure induction, including temperature sensitivity, were not noticed. She had severe intellectual and psychomotor retardation but has no paralysis. Muscle tonus and deep tendon reflexes were also normal. Magnetic resonance imaging showed moderate diffuse brain atrophy. She is now attending a sheltered workshop.

\section{Mutational analysis}

Methods for mutational analysis were described previously (Sugawara et al., 2001b). Briefly, genomic DNA was extracted from heparin-treated blood samples of affected and unaffected individuals, amplified by PCR, and analyzed by direct sequencing. PCR primers were designed to amplify all 26 coding exons of SCN2A. The mutation was confirmed as a heterozygous one as follows. The PCR product was subcloned into pCR 2.1 vecto-TOPO by TOPO TA cloning (Invitrogen, Carlsbad, CA), and independent subclones were sequenced by M13 forward (5' -TTGTAAAACGACGGCCAG) and reverse (5'-ACACAGGAAACAGCTATG) primers. The sequence data using in this study have been submitted to the GenBank databases under accession numbers X65361, AB098335, NM_000816, and NM_001037.

\section{EEG recordings}

EEG was recorded with a 10-20 system during both awake and sleep states. Video monitoring was conducted to record the ictal behavioral changes, if any, simultaneously with EEG.

\section{Plasmid construction and transfection}

The SCN2A cDNA encoding the human brain $\mathrm{Na}^{+}$channel $\alpha_{\text {II }}$ subunit ( $\mathrm{Na}_{\mathrm{v}} 1.2$; GenBank accession number M94055; Ahmed et al., 1992) was inserted into the NotI site of a pCI-neo plasmid vector (Promega, Madison, WI). The mutation of SCN2A corresponding to R102X was introduced into the wild-type (WT) construct with the QuikChange sitedirected mutagenesis kit (Stratagene, La Jolla, CA) according to the manufacturer's instructions. Flag-tagged R102X constructs were made in a pcDNA3 plasmid vector (Invitrogen) in which a Flag epitope was located at the $\mathrm{N}$ terminus (R102X-FlagN) or C terminus (R102X-FlagC). In the R102X-FlagC construct, an aspartic acid replaces the arginine 102 and is followed by a flag epitope sequence and a stop codon. Full insert sequences for WT as well as mutants were confirmed by dideoxynucleotide sequencing. Plasmid DNAs for transfection were isolated with a Plasmid Maxi kit (Qiagen, Hilden, Germany). For the construction of CD8-IRS-hb2, an 871 bp fragment of human CD8 was amplified by PCR with primers CD8F1 (5'-ATATGCTAGCGGAGCGCGTCATGGCCTTAC-3') and CD8R1 (5'-CGGAATTCACCCCGCCCCCACTAAAATAA-3') using EBO-pCD-Lue2 (59564; American Type Culture Collection, Manassas, VA) as a template. Underlined sequences indicate the recognition sequences of NheI and EcoRI, respectively. The PCR product was digested with NheI$E c o$ RI and subcloned into the bicistronic plasmid pIRES (Clontech, Palo Alto, CA) to obtain pCD8-IRES. Total RNA of the human heart was reversetranscribed with Superscritpt II (Invitrogen) using the random hexamers, and the first-strand cDNA was amplified with primers $1 \mathrm{~F}$ ( $5^{\prime}$-CCACCCGACTAACATCTCAG-3') and 4R (5'-GGAGACGGGACACGGAG$\left.3^{\prime}\right)$. A 734 bp product was subcloned into pCR2.1 (Invitrogen), and the SpeI-NotI fragment was subcloned into the pCD8-IRES using XbaI/NotI sites. The DNA sequence the final construct $\mathrm{pCD} 8$-IRS-h $\beta 2$ was verified by the dideoxy sequencing. For patch-clamp experiments, plasmids bearing WT and R102X full-length $\alpha$-subunit cDNA as well as an equimolar pEGFPN1 vector (Clontech) as a marker were transiently transfected into human embryonic kidney 293 (HEK293) cells using LipofectAMINE 2000 (Invitrogen) as recommended by the manufacturer. For the coexpression experiments using WT and R102X (WT $+\mathrm{R} 102 \mathrm{X}$ ), the equimolar plasmids bearing each of WT $(20 \mu \mathrm{g})$ and R102X $(20 \mu \mathrm{g})$ cDNA were simultaneously transfected into HEK293 cells, and channel function was compared with HEK293 cells transfected with only equimolar $(20 \mu \mathrm{g})$ WT plasmid. For patch-clamp analysis of $\alpha$ and $\beta$ subunits of the sodium channel, HEK293 cells stably expressing the human $\mathrm{Na}^{+}$channel $\beta 1$ subunit (HEK-h $\beta 1$; Akai et al., 2000) were transiently transfected with WT, R102X, and the $\beta 2$ subunit. The $\beta 2$ construct pIRES-CD8-hb2 was tagged with CD8 to visually identify the cells expressing the $\beta 2$ subunit by using M-450 CD8 Dynabeads (Dynal, Oslo, Norway).

\section{Patch-clamp analysis}

Preparations. HEK293 cells were plated on poly-L-lysine-coated glass coverslips (Biocoat Cellware poly-L-lysine $12 \mathrm{~mm}$ coverslip; Becton Dickinson Labware, Bedford, MA) and maintained in culture medium (DMEM supplemented with $10 \%$ fetal bovine serum) in humidified 5\% $\mathrm{CO}_{2}$ for $24-48 \mathrm{hr}$.

Electrical recording. Coverslips were anchored in the recording chamber filled with the external solution using silicone grease. Transfected HEK293 cells for the recordings were selected using the green fluorescence protein (GFP) fluorescence signal under an inverted microscope (IX70; Olympus Optical, Tokyo, Japan). To minimize space-clamp problems, isolated cells with strong GFP fluorescence were selected, and GFPpositive cells in syncytia were not considered. The external solution contained (in mM): $135 \mathrm{NaCl}, 2.0 \mathrm{CaCl}_{2}, 1.0 \mathrm{MgCl}_{2}, 5.0$ glucose, and 10 HEPES. The solution was adjusted to $\mathrm{pH} 7.4$ with $\mathrm{NaOH}$, and the osmolarity was $281 \mathrm{mOsm}$. Pipette electrodes were made from borosilicate glass capillary tubes $(0.8-1.0 \mathrm{~mm}$ inner diameter; Hilgenberg $\mathrm{GmbH}$, 
Marsfeld, Germany) using a multistep horizontal puller (P-97; Sutter Instrument Co., Novato, CA). The composition of the pipette solution was (in mM): $135 \mathrm{CsF}, 10 \mathrm{NaCl}$, and 5 HEPES-acid. The $\mathrm{pH}$ was adjusted to 7.0 with $\mathrm{CsOH}$, and the osmolarity was $276 \mathrm{mOsm}$. Pipette resistance was 1.0-3.5 $\mathrm{M} \Omega$ when filled with internal pipette solution. The outer wall of the pipette, except the very tip, was coated with dental wax to reduce stray capacitance (GC Corp., Tokyo, Japan). The reference electrode was an $\mathrm{Ag}-\mathrm{AgCl}$ pellet in a well that was connected to the bath using a $150 \mathrm{~mm} \mathrm{NaCl}$-filled agar bridge. Currents were recorded using an Axopatch 1D amplifier (Axon Instruments, Burlingame, CA). Capacitative currents and series resistances were electronically compensated. Current and voltage signals were filtered using a low-pass Bessel filter with a cutoff frequency at $10 \mathrm{kHz}$ and stored on a hard disk in V450JS2 (Iiyama, Nagano, Japan); pclamp 6.0 software (Axon Instruments) was used throughout. The values in all pulse protocols were programmed on the computer, and all data were compensated for liquid junction potentials $(-1 \mathrm{mV}$ on average) after recordings. Peak currents of $\geq 200 \mathrm{pA}$ were considered as the signals arising from transfected $\mathrm{Na}^{+}$channels to eliminate any potential contribution from the small $(\sim 50 \mathrm{pA})$, tetrodotoxinsensitive $\mathrm{Na}^{+}$currents present in a fraction of untransfected HEK293 cells. All experiments were performed at room temperature $\left(22^{\circ} \mathrm{C}\right)$. In the present experiments, a maximum peak current did not exceed 1.7 $\mathrm{nA}$, and voltage errors stemming from series resistance estimated were $<6 \mathrm{mV}$.

Data analysis for conductance-voltage relationship. $\mathrm{Na}^{+}$currents were evoked by $10 \mathrm{msec}$ depolarizations to various test potentials ( -80 to 20 $\mathrm{mV}$ ) from a holding potential of $-120 \mathrm{mV}$. Current-voltage relationships were constructed after subtraction of leak currents. Step depolarization produced an ohmic conductance only below $-60 \mathrm{mV}$ in our experimental condition. Leak currents at individual potentials were estimated from the linear regression of data points of $-80,-70$, and -60 $\mathrm{mV}$. Sodium conductance $\left(g_{\mathrm{Na}}\right)$ was calculated according to the equation, $g_{\mathrm{Na}}=I_{\mathrm{Na}} /\left(V_{\mathrm{g}}-V_{\mathrm{r}}\right)$, where $I_{\mathrm{Na}}$ is the peak amplitude of the $\mathrm{Na}^{+}$ current; $V_{\mathrm{g}}$ is the test potential; and $V_{\mathrm{r}}$ is the reversal potential for $\mathrm{Na}^{+}$. In a double-pulse protocol, two depolarizing pulses (step to $10 \mathrm{mV}, 10$ $\mathrm{msec}$ in duration) with various interpulse intervals $(0.5-20 \mathrm{msec})$ were successively applied to activate $\mathrm{Na}^{+}$currents. The amplitude of $\mathrm{Na}^{+}$ currents evoked by the second pulse $(I)$ was normalized by the amplitude of $\mathrm{Na}^{+}$currents evoked by the first pulse $\left(I_{\max }\right)$, and $I / I_{\max }$ is expressed as recovery ratios.

\section{Western blot analysis}

Transfected cell samples for Western blotting were sonicated in $1 \mathrm{~mm}$ Tris, $\mathrm{pH}$ 8.0, with a protease inhibitor mixture tablet (Roche Molecular Biochemicals, Mannheim, Germany), centrifuged at $3000 \times g$ for 5 min at $4^{\circ} \mathrm{C}$ to remove insoluble material. The supernatants were collected and run on $4-20 \%$ gradient gels (Daiichi Pure Chemicals Co., Ltd., Tokyo, Japan) for wild-type $\mathrm{Na}_{\mathrm{v}} 1.2$ and $15-25 \%$ gradient gels for Flag-tagged R102X (R102X-FlagN and R102X-FlagC) and then transferred onto a nitrocellulose filter ( $0.45 \mu \mathrm{m}$; Schleicher \& Schuell, Dassel, Germany). After blocking, membranes were processed through sequential incubations with anti- $\mathrm{Na}_{\mathrm{v}} 1.2$ (1:200 dilution; Alomone Labs, Jerusalem, Israel) or anti-Flag mouse monoclonal antibody (1:1000 dilution; Sigma, St. Louis, MO) for $1 \mathrm{hr}$ and then with $0.4 \mu \mathrm{g} / \mathrm{ml}$ horseradish peroxidaseconjugated anti-rabbit or anti-mouse IgG (Santa Cruz Biotechnology, Santa Cruz, CA). The anti- $\mathrm{Na}_{\mathrm{v}} 1.2$ rabbit polyclonal antibody used was raised against residues $467-485$ of human brain $\mathrm{Na}_{\mathrm{v}} 1.2$. Immunoreactive proteins on the filter were visualized using Western Lightning Plus chemiluminescence reagent (PerkinElmer Life Sciences, Boston, MA).

\section{Immunocytochemistry}

HEK293 cells transfected with $\mathrm{Na}_{\mathrm{v}} 1.2$, R102X-FlagC, or both were fixed in $4 \%$ paraformaldehyde for $15 \mathrm{~min}$ and treated by $0.1 \%$ Triton X-100 (Nakalai Tesque, Kyoto, Japan). Nonspecific binding was blocked with $3 \%$ normal goat serum and $3 \%$ gelatin in PBS. Then cells were incubated for $1 \mathrm{hr}$ with anti-Na 1.2 polyclonal antibody (1:30 dilution; Alomone Labs) and anti-Flag mouse monoclonal antibody (1:200 dilution; Sigma). The secondary antibodies were Alexa488-conjugated chicken anti-rabbit (1:200; Molecular Probes, Eugene, OR) and Alexa594-
A

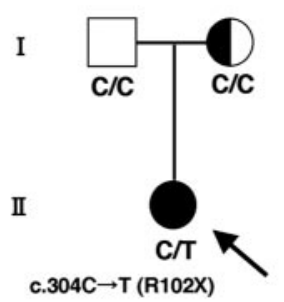

B
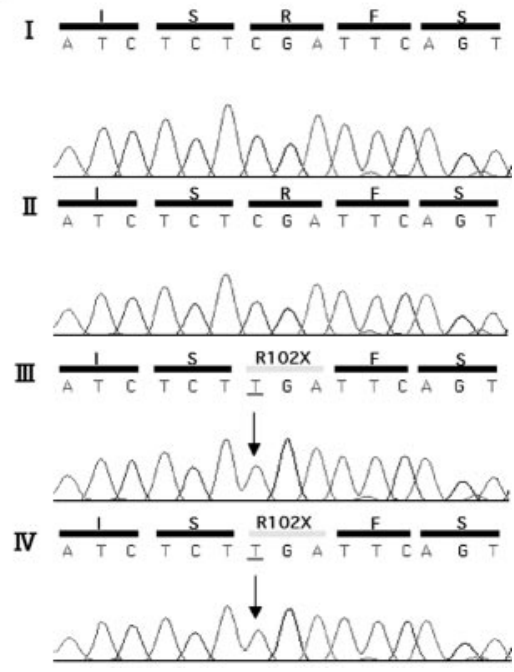

Figure 1. Nonsense mutation of SCN2A identified in a Japanese patient with intractable childhood epilepsy and severe mental decline. A, Pedigree tree of the Japanese family with febrile seizure (mother) and the intractable epilepsy (proband, arrow). The c.304C $\rightarrow$ T nonsense mutation was observed only in the proband. Circles, Females; square, male; filled circle, localization-related epilepsy; half-filled circle, febrile seizure. $B$, Electropherograms of the nonsense mutation R102X. Genomic PCR products were subcloned into a plasmid vector and sequenced separately (see Materials and Methods). The sequences from independent clones are shown in I-IV as examples. I and II show wild-type sequences, whereas III and IV show mutated sequences in which the arginine residue is altered to a stop codon. Fifteen of 37 subclones showed the nonsense mutation alike in III and IV. An examination of blood taken from the proband in another occasion reproduced a similar result, further confirming the existence of the $\mathrm{c.304C} \rightarrow \mathrm{T}(\mathrm{R} 102 \mathrm{X})$ nonsense mutation in this patient.

conjugated goat anti-mouse antibody (1:200; Molecular Probes). Labeling was viewed with a confocal laser scanning microscope (TCS SP2; Leica, Nussloch, Germany).

\section{Results}

\section{Nonsense mutation of SCN2A in intractable epilepsy}

We performed mutational analyses on the complete 26 exons of SCN1A in a total of 60 patients diagnosed with intractable childhood epilepsies including SMEI (Sugawara et al., 2002; Fujiwara et al., 2003), and 20 patients without any mutations of SCN1A were further screened for $S C N 2 A$. In one of these samples, we found a heterozygous nonsense mutation, c.304C $\rightarrow$ T, resulting in an intragenic stop codon Arg-102Stop (R102X; Fig. 1). This mutation was not observed in 86 healthy control chromosomes. The mother and father of this patient had no mutation in the coding region of $S C N 2 A$, indicating that the $\mathrm{R} 102 \mathrm{X}$ is a de novo mutation. We further confirmed that the patient had no mutations of the voltage-gated sodium channel $\beta 1$ subunit (SCN1B) or the $\mathrm{GABA}_{\mathrm{A}}$ receptor $\gamma 2$ subunit $(G A B R G 2)$ genes in which mutations were reported in patients with GEFS+, febrile seizures, and childhood absence epilepsy (Baulac et al., 2001; Wallace et al., 2001a; Harkin et al., 2002). The patient with the SCN2A-R102X mutation has severe mental decline and autistic behavior, in addition to the intractable seizure disorder, and exhibits moderate diffuse brain atrophy (for details, see Materials and methods). The EEG of this patient shows the focal seizure onset (Fig. 2). The epilepsy was diagnosed as "localization-related epilepsy with secondarily generalized convulsive seizures."

The mutated residue Arg-102 is located at the N-terminal tail of the $\mathrm{Na}_{\mathrm{v}} 1.2$ protein, yielding a truncated peptide that terminates before the occurrence of the first transmembrane segment D1S1 (Fig. 3A). To investigate the function and distribution of 


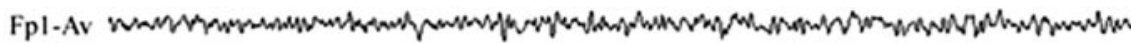

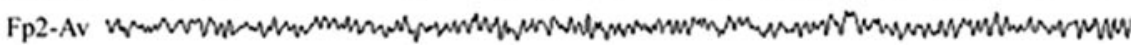

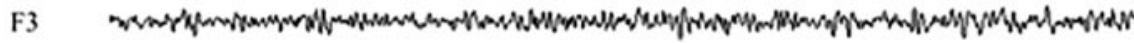

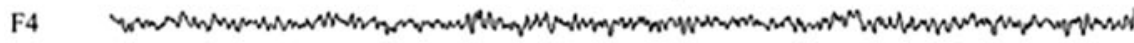

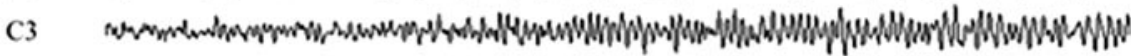

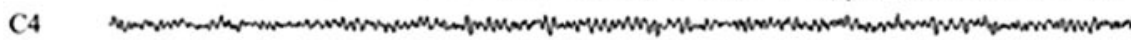

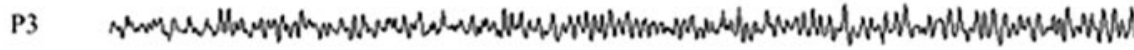

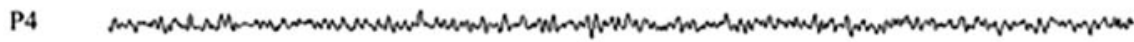

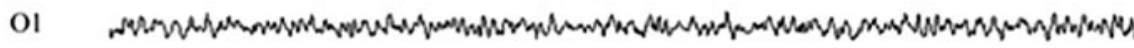

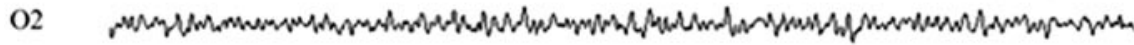

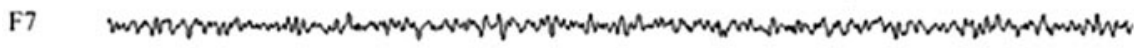

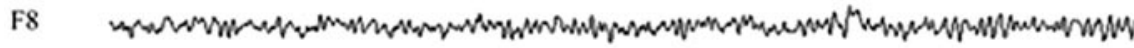

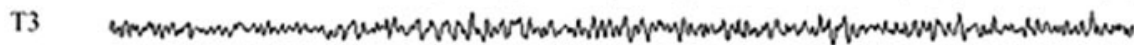

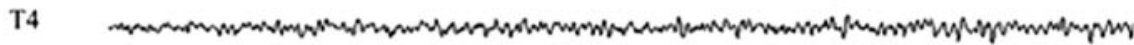

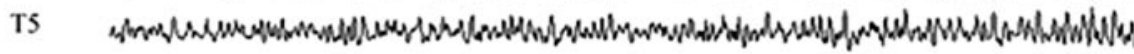

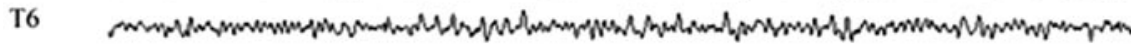
FZ

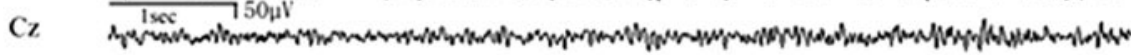

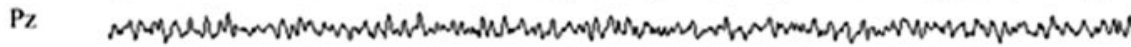

Figure 2. Initial phase of the ictal EEG of the patient with the R102X mutation of SCN2A. The EEG recorded during a convulsive seizure lasting 60 sec showed recruiting spike activities in the centroparietomidtemporal region on the left side before bilateralization. All the odd-numbered EEG electrodes were placed on the left side of the head, and even-numbered electrodes were placed on the right. She opened her eyes when her eyes were deviated toward the right along with retraction of the mouth corner on the same side, and then the head turned to the left, followed by convulsive movements of the whole body.

A

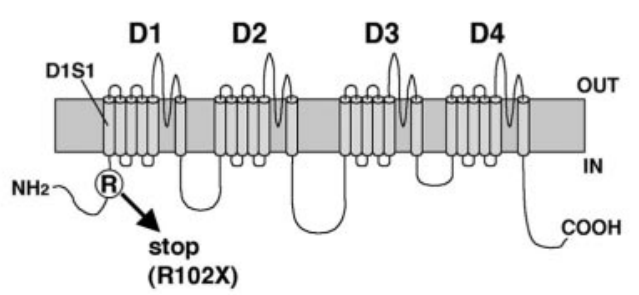

B

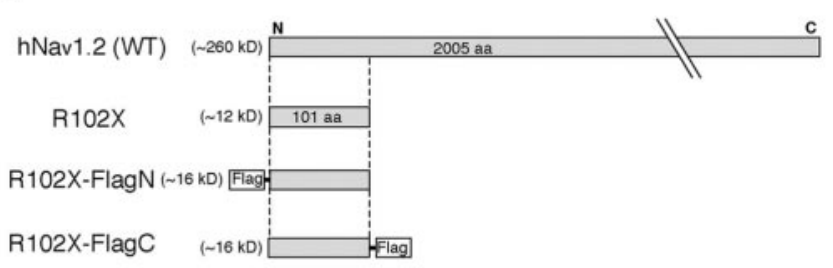

Figure 3. A, Schematic representation of the predicted folding topology of $\mathrm{Na}_{\mathrm{v}} 1.2 . \mathrm{R} 102 \mathrm{X}$ nonsense mutation identified in a patient with intractable childhood epilepsy and severe mental decline locates at the $\mathrm{N}$ terminus. $\mathrm{B}$, Schematic diagrams of human $\mathrm{Na}_{\mathrm{v}} 1.2$ expression constructs. Wild-type $\mathrm{Na}_{\mathrm{v}} 1.2\left(\mathrm{hNa}_{\mathrm{v}} 1.2\right)$, the truncated mutant protein $\mathrm{R} 102 \mathrm{X}$, and the two fusion proteins Flag-tagged at N-terminal end (R102X-FlagN) and C-terminal end (R102X-FlagC) were constructed for further analysis. For details, see Materials and Methods.

this truncated mutant protein, we constructed four expression vectors for wild-type $\mathrm{Na}_{\mathrm{v}} 1.2, \mathrm{R} 102 \mathrm{X}$, and R102X tagged with Flag at $\mathrm{N}$ and $\mathrm{C}$ termini (Fig. $3 B$ ).

\section{Dominant negative effect of the $\mathrm{R} 102 \mathrm{X}$ truncated protein}

To investigate the functional consequences of the truncated protein, we analyzed the electrophysiological properties of the hu- man brain WT Na 1.2 channel (Ahmed et al., 1992) and the R102X mutant expressed in the human cell line HEK293 using whole-cell patch-clamp recordings. $\mathrm{Re}$ cordings were initiated when the holding current was $<30 \mathrm{pA}$ after adopting the whole-cell configuration; this routinely required 5-10 min of the intracellular perfusion with fluoride. Figure $4 A$ shows the peak $\mathrm{Na}^{+}$currents in response to a depolarizing voltage step to $0 \mathrm{mV}$, from a holding potential of $-120 \mathrm{mV}$, for $\mathrm{WT} \mathrm{Na}_{\mathrm{v}} 1.2$ channels. The $\mathrm{Na}^{+}$current reached a peak within $1 \mathrm{msec}$ and inactivated within 5 msec, in accord with expectations (Ahmed et al., 1992). By contrast, no voltage-gated $\mathrm{Na}^{+}$currents were detected in cells expressing the R102X mutant channels, confirming that the truncated protein is nonfunctional (Fig. 4A). Given the heterozygous nature of the R102X mutation, we proceeded to examine cells expressing only the WT channel and cells coexpressing the WT channel and the R102X mutant protein (WT+R102X) aiming to disclose potential alterations introduced by the R102X mutant on the electrophysiological properties of the wild-type $\mathrm{Na}_{\mathrm{v}} 1.2$ channel. The currents were characterized by examining the peak $\mathrm{Na}^{+}$conductancevoltage $(G-V)$ relationship shown in Figure $4 B$. To compare the average of half-activation potentials between WT and WT+R102X, a half-activation potential for each cell was calculated by curve fitting and pooled. For the wild-type $\mathrm{Na}_{\mathrm{v}} 1.2$ channel, the $\mathrm{Na}^{+}$conductance increased with depolarizing voltages to a maximum at $10 \mathrm{mV}$, displaying a half-activation potential at $-22.6 \pm 2.4 \mathrm{mV}(n=8)$. The corresponding value for the currents measured from cells coexpressing WT and R102X proteins was $-25.5 \pm 3.6 \mathrm{mV}(n=7)$, a difference that was not statistically significant ( $p>0.05$; Fig. $4 B$ ).

Next, we investigated the steady-state voltage dependence of inactivation in which the test pulse of $-10 \mathrm{mV}$ was preceded by long ( $2 \mathrm{sec}$ ) depolarizing prepulses of various holding potentials. Steady-state inactivation increases sigmoidally as the potential of the prepulse is stepped toward more positive potentials (Fig. 4C). Half inactivation potentials $\left(\mathrm{V}_{1 / 2}\right)$ for the prepulse protocol were calculated and averaged (Fig. $4 D$ ). For the WT channel, $\mathrm{V}_{1 / 2}$ was $-68.7 \pm 3.2 \mathrm{mV}(n=12)$, whereas for the WT+R102X cotransfection, it was $-79.7 \pm 1.3 \mathrm{mV}(n=13)$, showing a statistically significant difference $(p=0.0016)$. These results indicate that the WT channel produces a hyperpolarizing shift of the inactivation curve when coexpressed with the R102X truncated protein. Such a shift of the steady-state inactivation would alter the fraction of $\mathrm{Na}^{+}$channels available for activation at physiological membrane potentials. This hyperpolarizing shift of the inactivation curve (Fig. 4C,D) measured in WT+R102X indicate that the $\mathrm{R} 102 \mathrm{X}$ truncated protein exerts a dominant negative effect on the wild-type channel, affecting the inactivation process and increasing the susceptibility of $\mathrm{Na}_{\mathrm{v}} 1.2$ channels to inactivate.

Next, we analyzed the voltage dependence of activation and inactivation for cotransfection of WT with Flag-tagged R102X (WT+R102X-FlagN or WT+R102X-FlagC) because Flagtagged R102X constructs were used for further analysis of expres- 
A

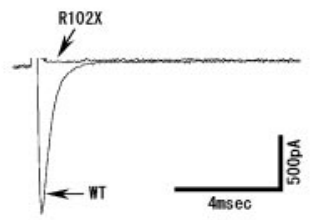

C

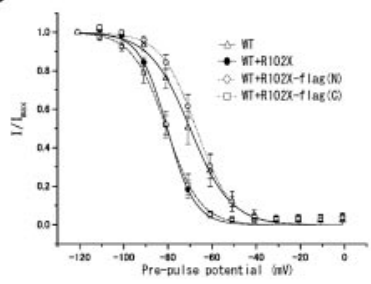

E

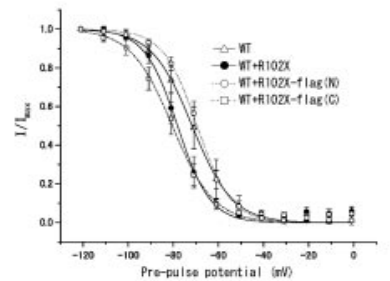

B

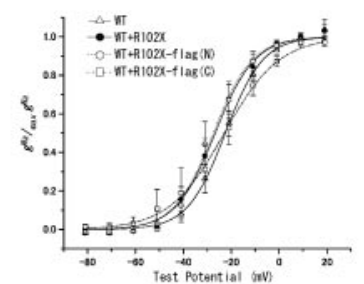

D
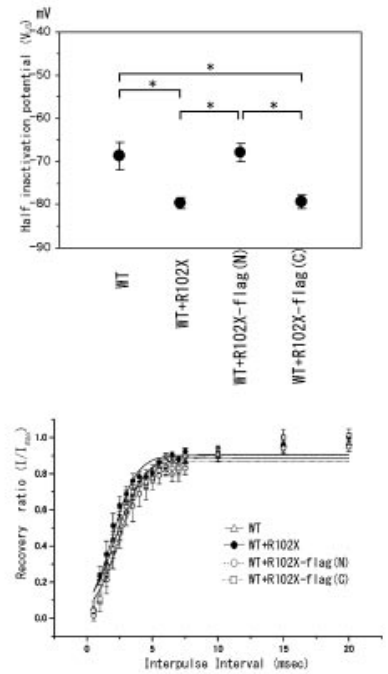

Figure 4. Voltage-gated sodium currents recorded from HEK293 cells expressing wild-type human $\mathrm{Na}_{\mathrm{v}} 1.2$ only (WT), coexpressed wild-type and mutant (WT+R102X, WT+R102XFlagN, WT + R102X-FlagC), and mutant only (R102X). A, Sodium currents of the WT channel and R102X mutant protein. Currents were evoked by a step depolarization to $0 \mathrm{mV}$ from a holding potential of $-120 \mathrm{mV}$. B, Peak sodium conductance-voltage relationships for WT (open triangle), WT+R102X (filled circle), WT+R102X-FlagN (open circle), and WT + R102X-FlagC (open square). The data points represent the average of $g_{\mathrm{Na}}$. The lines represent the least squares fit of the data to a Boltzmann function, according to the equation $g_{\mathrm{Na}} /_{\max } g_{\mathrm{Na}}=1 /\left\{1+\exp \left[V g_{0.5}-\right.\right.$ $\left.V_{\mathrm{g}}\right] / \mathrm{kg}$, where ${ }_{\max } \mathrm{g}_{\mathrm{Na}}$ is the maximum value for the $\mathrm{Na}^{+}$conductance, $g_{\mathrm{Na}} ; V g_{0.5}$ is the halfactivation potential at which $g_{\mathrm{Na}}$ is $0.5_{\mathrm{max}} g_{\mathrm{Na}}$; and $\mathrm{kg}$ is the slope factor. C, Steady-state voltage dependence of inactivation for each cell. Cells were prepulsed for 2 sec at various holding potentials (from -120 to $20 \mathrm{mV}$ in $10 \mathrm{mV}$ increments), and then $\mathrm{Na}^{+}$current was evoked by a step depolarization to $-10 \mathrm{mV} . I_{\max }$ is the peak amplitude of the $\mathrm{Na}^{+}$current measured at a holding potential of $-120 \mathrm{mV}$. The data points represent the average of $I / I_{\max }$. The solid lines represent the least squares fit of the data to a Boltzmann function, according to the equation $I / I_{\max }=1 /\left\{1+\exp \left[\left(V_{\mathrm{h}}-V_{1 / 2}\right) / k\right]\right\}$, where $I_{\max }$ is the magnitude of the peak Na ${ }^{+}$current observed at a holding potential of $-120 \mathrm{mV} ; V_{\mathrm{h}}$ is the holding potential; $V_{1 / 2}$ is the potential at which the $\mathrm{Na}^{+}$current is half-maximal, and $k$ is the slope factor. $D, V_{1 / 2}$ values for each cell with a long prepulse ( 2 sec) shown in C $(n=12$ or 13). Each point is given as mean \pm SEM. * Statistical difference at $1 \%$ level. $E$, Steady-state voltage dependence of inactivation for each cell. Cells were pre pulsed for $200 \mathrm{msec}$ at various holding potentials (from -120 to $20 \mathrm{mV}$ in 10 $\mathrm{mV}$ increments), and then $\mathrm{Na}^{+}$current was evoked by a step depolarization to $-10 \mathrm{mV}$. Solid lines were fitted by the equation shown in C.F, Recovery from inactivated state. Recovery ratios from the inactivated state $\left(I / I_{\max }\right)$ were measured for various interpulse intervals. The curves were fitted using a Boltzmann function as described above. Each point is given as mean \pm SEM.

sion and localization of the truncated protein. Activation and inactivation curves for WT+R102X-FlagN and WT+R102XFlagC are overlaid on Figure 4, $B$ and $C$. For WT+R102X-FlagN, the $\mathrm{Na}^{+}$conductance increased with depolarizing voltages to a maximum at $10 \mathrm{mV}$, displaying a half-activation potential at $-27.3 \pm 3.7 \mathrm{mV}(n=7)$. The corresponding value for the currents measured from cells coexpressing WT and WT+R102XFlagC proteins was $-26.1 \pm 5.8 \mathrm{mV}(n=6)$, a difference that was not statistically significant $(p>0.05$ compared with WT; Fig. $4 B)$. Surprisingly, the inactivation curve for WT+R102X-FlagN overlapped with that for WT, whereas the curve for WT+R102X-

FlagC negatively shifted and overlapped with the curve for $\mathrm{WT}+\mathrm{R} 102 \mathrm{X}$ (Fig. 4C). The half-inactivation potential was $-67.9 \pm 2.0 \mathrm{mV}(n=13)$ for $\mathrm{WT}+\mathrm{R} 102 \mathrm{X}-$ FlagN and $-79.3 \pm 1.6$ $\mathrm{mV}(n=13)$ for WT+R102X-FlagC (Fig. 4D). These data using two Flag-tagged fusion proteins show that only the R102X-FlagC displays a functional effect comparable with that of untagged $\mathrm{R} 102 \mathrm{X}$ and indicate that the location of the tag disrupts the dominant negative effect of R102X.

To assess the contribution of slow inactivation to the observed hyperpolarizing shift of the half-inactivation potential, we repeated the same protocol by using short $(200 \mathrm{msec})$ depolarizing prepulses of various holding potentials (Fig. $4 E$ ). The result confirmed that the dominant negative effect of the R102X truncated protein on the wild-type channel was affected by the location of the Flag tag. The $\mathrm{V}_{1 / 2}$ for the WT channel was $-70.4 \pm 4.2(n=6)$, whereas the $\mathrm{V}_{1 / 2}$ of the $\mathrm{WT}+\mathrm{R} 102 \mathrm{X}$ cotransfection was $-79.8 \pm$ $2.4 \mathrm{mV}(n=6)$, showing a statistically significant difference $(p=$ $0.039)$. The half-inactivation potential for WT+R102X-FlagN was $-69.4 \pm 1.8 \mathrm{mV}(n=6)$, and that for WT+R102X-FlagC was $-80.1 \pm 2.3 \mathrm{mV}(n=6)$. There was no statistically significant difference of half-inactivation potentials between short and long prepulses in all cases. These results using short and long prepulse protocols indicate that the process underlying the hyperpolarizing shift of the inactivation curve in WT+R102X and $\mathrm{WT}+\mathrm{R} 102 \mathrm{X}$-FlagC is essentially complete within $200 \mathrm{msec}$, and there is no appreciable involvement of slow inactivation.

To discern any effects on the recovery from inactivation, we compared the recovery times from the inactivated state by using a double-pulse protocol. We defined half-recovery intervals as the interpulse intervals at which the $\mathrm{Na}^{+}$currents retrieved $50 \%$ of the control value. Half-recovery intervals were $2.3 \pm 0.23 \mathrm{msec}$ for WT $(n=6), 2.0 \pm 0.27 \mathrm{msec}$ for WT+R102X $(n=6), 2.6 \pm$ $0.4 \mathrm{msec}$ for WT+R102X-FlagN $(n=6)$, and $2.5 \pm 0.13 \mathrm{msec}$ for $\mathrm{WT}+\mathrm{R} 102 \mathrm{X}-\mathrm{FlagC}(n=5$; Fig. $4 F)$. No significant differences of recovery time were detected among the different samples $(p>$ $0.05)$. We further examined the occurrence of persistent currents that were previously reported in $\mathrm{Na}_{\mathrm{v}} 1.1$ channels with GEFS+ mutations (Lossin et al., 2002). Again, no persistent current was observed for any of the samples.

\section{Evaluation of expression levels for wild-type $\mathrm{Na}_{\mathrm{v}} 1.2$ and truncated R102X proteins in HEK293 cells}

To analyze the expression levels and patterns of the wild-type $\mathrm{Na}_{\mathrm{v}} 1.2$ and truncated R102X proteins in the HEK293 cells used in the patch-clamp recordings, we performed Western blot analysis. To confirm that no read-through in the R102X expression construct occurred, we examined the pattern of protein expression in HEK293 cell lysates transfected with WT Na $1.2(\sim 260 \mathrm{kDa})$, the R102X mutant, and no expression construct as a control (Fig. $5 A$ ). The anti-human $\mathrm{Na}_{\mathrm{v}} 1.2$ antibody detected a positive signal above the $250 \mathrm{kDa}$ molecular weight marker. In contrast, neither untransfected cells nor the R102X mutant-transfected cells displayed any signal, suggesting that no read-through actually occurred.

To confirm that the wild-type $\mathrm{Na}_{\mathrm{v}} 1.2$ channels expressed by the transfected construct are actually inserted into cell membrane even in the cotransfected condition with R102X-FlagC, the membrane and the cytoplasmic fractions of the cell lysate were blotted and probed with anti- $\mathrm{Na}_{\mathrm{v}} 1.2$ antibody (Fig. $5 B$ ). The wild-type $\mathrm{Na}_{\mathrm{v}} 1.2$ channels were detected only in the membrane fraction. Expression of the untagged R102X truncated protein in HEK293 cells was not confirmed by Western blot analysis because an antibody against the $101 \mathrm{~N}$-terminal residues of $\mathrm{Na}_{\mathrm{v}} 1.2$ is not avail- 
A

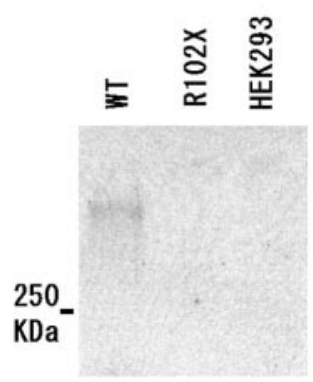

B

250 $\mathrm{KDa}^{-}$
C

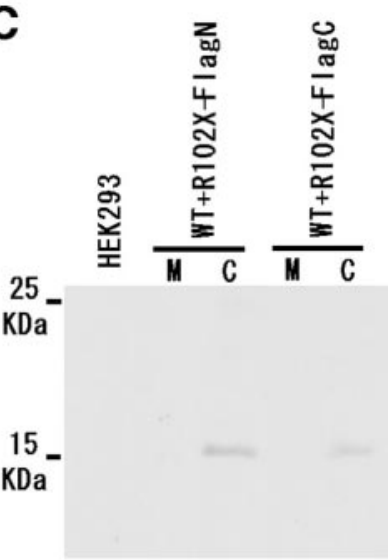

Figure 5. Western blot analysis of wild type $\mathrm{Na}_{\mathrm{v}} 1.2$ (WT) and the truncated mutant proteins R102X and R102X tagged with Flag at the N terminus (R102X-FlagN) and C terminus (R102X-FlagC) in HEK293 cells. A, WT, R102X, and untransfected HEK293 cells probed with anti- $\mathrm{Na}_{\mathrm{v}} 1.2$ rabbit polyclonal antibody raised against residues $467-485$ of human $\mathrm{Na}_{\mathrm{v}} 1.2$. HEK293 cells transfected with a wild-type $\mathrm{Na}_{\mathrm{v}} 1.2$-expressing construct show a positive signal above the $250 \mathrm{kDa}$ molecular weight marker, whereas the R102X mutant-transfected cells and untransfected cells displayed no signal. B, Membrane fraction (M) and cytoplasmic fraction (C) of WT+R102X-FlagC cotransfected cells probed with anti-Na 1.2 rabbit polyclonal antibody. A band at $\sim 270 \mathrm{kDa}$ was observed in the membrane fraction. C, Membrane fraction (M) and cytoplasmic fraction (C) of WT+R102X-FlagN and WT + R102X-FlagC probed with an anti-Flag monoclonal antibody. Distinct bands were observed at $\sim 16 \mathrm{kDa}$ in cytoplasmic fractions.
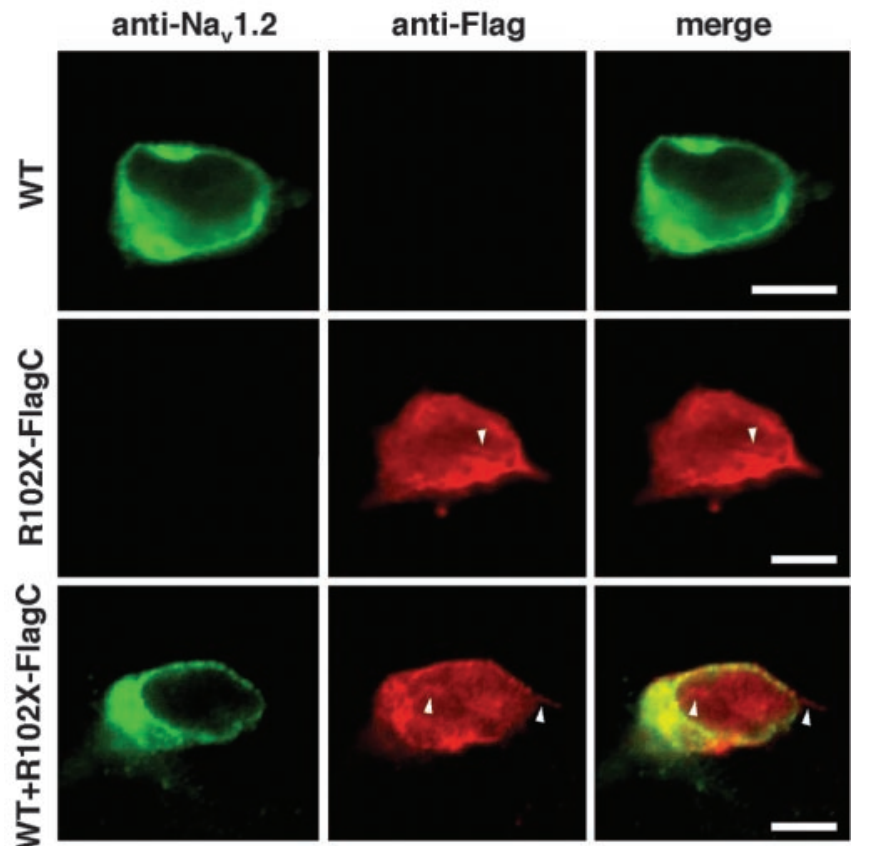

Figure 6. Immunocytochemistry of HEK293 cells transfected with expression constructs for wild-type $\mathrm{Na}_{\mathrm{v}} 1.2$ (WT) and the truncated mutant proteins R102X tagged with Flag at the $\mathrm{C}$ terminus (R102X-FlagC) and cotransfected cells (WT+R102X-FlagC). Each cell was doublestained by anti- $\mathrm{Na}_{\mathrm{v}} 1.2$ rabbit polyclonal antibody (green) and anti-Flag monoclonal antibody (red). Red fluorescence shows cytoskelton-like filament structures (arrowheads) in R102XFlagC and WT+R102X-FlagC. Scale bars, $8 \mu \mathrm{m}$.

able. Notwithstanding, we constructed the R102X tagged with the Flag epitope at $\mathrm{N}$ and $\mathrm{C}$ termini and confirmed the expression of the Flag-R102X fusion protein with an apparent molecular weight of $\sim 16 \mathrm{kDa}$, consistent with the expression of the untagged R102X truncated protein in HEK293 cells. Both R102X-FlagN and R102XFlagC were detected in cytoplasmic fractions of cotransfected cells (Fig. 5C).

Subcellular localization of wild-type $\mathrm{Na}_{\mathrm{v}} 1.2$ and truncated $\mathrm{R} 102 \mathrm{X}$ proteins To visualize the location of wild-type $\mathrm{Na}_{\mathrm{v}} 1.2$ and truncated R102X proteins in the same cell, the HEK293 cells transfected with the expression constructs for wild-type $\mathrm{Na}_{\mathrm{v}} 1.2$, R102X-FlagC, and both were double-stained by anti-Na 1.2 and anti-Flag antibodies. $\mathrm{Na}_{\mathrm{v}} 1.2$ and R102X-FlagC display different localization patterns in cotransfected cells, WT+R102X-FlagC (Fig. 6, bottom). The distributions of $\mathrm{Na}_{\mathrm{v}} 1.2$ and R102X-FlagC were not changed by cotransfection. Interestingly, the red signal (anti-Flag) was not uniformly diffuse but exhibited a granular and cytoskeletal filament-like structure in both R102X-FlagC and WT+R102X-FlagC (Fig. 6, arrowheads).

Effects of coexpression of $\boldsymbol{\beta}$ subunits on the functional properties of $\mathrm{Na}_{\mathrm{v}} 1.2$ and $\mathrm{Na}_{\mathrm{v}} 1.2$ with $\mathrm{R} 102 \mathrm{X}$

To investigate the functional consequences of the truncated protein in the presence of the accessory subunits, we analyzed the electrophysiological properties of the WT and WT + R102X coexpressed with $\beta 1$ and $\beta 2$ subunits in HEK293 cells using whole-cell patch-clamp recordings (see Materials and Methods). Recordings were performed under the same condition as described above. The currents were characterized by examining the peak $\mathrm{Na}^{+} G-V$ relationship shown in Figure 7A. A half-activation potential for each cell was calculated by curve fitting and pooled. For WT $+\beta 1+\beta 2$, the $\mathrm{Na}^{+}$conductance increased with depolarizing voltages to a maximum at $10 \mathrm{mV}$, displaying a halfactivation potential at $-25.8 \pm 1.7 \mathrm{mV}(n=7)$. The corresponding value for the currents measured from $\mathrm{WT}+\mathrm{R} 102 \mathrm{X}+\beta 1+\beta 2$ was $-21.1 \pm 2.7 \mathrm{mV}(n=7)$, a difference that was not statistically significant $(p>0.05)$. Next, we investigated the steady-state voltage dependence of inactivation in which the test pulse of $-10 \mathrm{mV}$ was preceded by long $(2 \mathrm{sec})$ depolarizing prepulses of various holding potentials increased sigmoidally as the potential of the prepulse was stepped toward more positive potentials (Fig. $7 B$ ). $V_{1 / 2}$ values for the prepulse protocol were calculated and averaged. For $\mathrm{WT}+\beta 1+\beta$, $\mathrm{V}^{1 / 2}$ was $-69.3 \pm 2.3 \mathrm{mV}(n=8)$, and for $\mathrm{WT}+\mathrm{R} 102 \mathrm{X}+\beta 1+\beta 2$ cotransfection, it was $-67.1 \pm 2.4 \mathrm{mV}(n=8)$, a difference that was not statistically significant $(p>0.05)$. Steady-state inactivation by short (200 msec) depolarizing prepulses was also analyzed (Fig. 7C). $\mathrm{V}_{1 / 2}$ for $\mathrm{WT}+\beta 1+\beta 2$ was $-66.4 \pm 1.8 \mathrm{mV}(n=8)$, and for $\mathrm{WT}+\mathrm{R} 102 \mathrm{X}+\beta 1+\beta 2$ cotransfection, it was $-64.7 \pm 3.6 \mathrm{mV}(n=$ $8)$, a difference that was again not statistically significant $(p>0.05)$. To discern any effects on the recovery from inactivation, we compared the recovery times from the inactivated state by using a double-pulse protocol. We defined half-recovery intervals as the interpulse intervals at which the $\mathrm{Na}^{+}$currents retrieved $50 \%$ of the control value. Half-recovery intervals were $1.9 \pm 0.1 \mathrm{msec}$ for $\mathrm{WT}+\beta 1+\beta 2(n=7)$ and $2.6 \pm 0.2 \mathrm{msec}$ for $\mathrm{WT}+\mathrm{R} 102 \mathrm{X}+\beta 1+\beta 2$ $(n=5$; Fig. 7D). No significant differences of recovery time were detected among the different samples $(p>0.05)$.

\section{Discussion}

An intriguing correlation appears to be emerging between the severity of the epileptic phenotypes and the nature of the mutations in the genes encoding voltage-gated sodium channels. In 
A
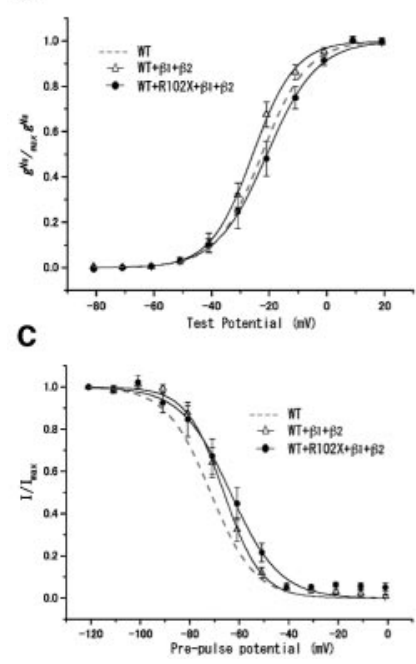

D
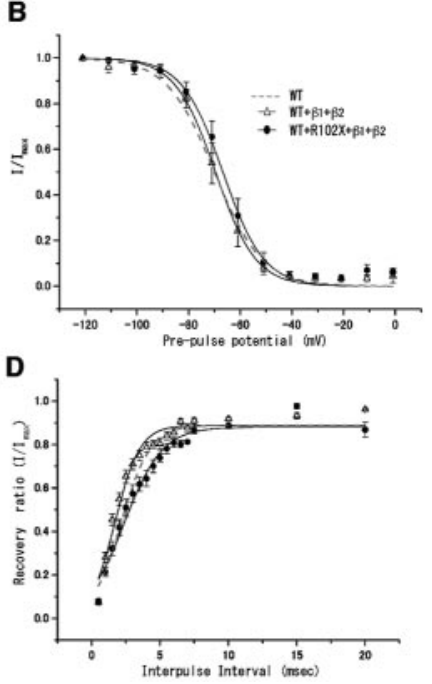

Figure 7. Effects of coexpression of $\beta$ subunits on the functional properties of $\mathrm{Na}_{\mathrm{v}} 1.2$ $\left(\mathrm{WT}+\beta 1+\beta 2\right.$ ) and $\mathrm{Na}_{\mathrm{v}} 1.2$ with $\mathrm{R} 102 \mathrm{X}$ (WT $\left.+\mathrm{R} 102 \mathrm{X}+\beta 1+\beta 2\right)$. A, Peak sodium conductance-voltage relationships for $\mathrm{WT}+\beta 1+\beta 2$ (open triangle) and $\mathrm{WT}+\mathrm{R} 102 \mathrm{X}+\beta 1+\beta 2$ (filled circle). Sodium currents were evoked by step depolarizations from a holding potential of $-120 \mathrm{mV}$. The data points represent the average of $g_{\mathrm{Na}}$. The lines represent the least squares fit of the data to a Boltzmann function, according to the equation shown in Figure 4B. B, Steadystate voltage dependence of inactivation for each cell. Cells were prepulsed for 2 sec at various holding potentials (from - 120 to $20 \mathrm{mV}$ in $10 \mathrm{mV}$ increments), and then $\mathrm{Na}^{+}$current was evoked by a step depolarization to $-10 \mathrm{mV} . I_{\max }$ is the peak amplitude of the $\mathrm{Na}^{+}$current measured at a holding potential of $-120 \mathrm{mV}$. The data points represent the average of $/ / I_{\max }$. The solid lines represent the least squares fit of the data to a Boltzmann function, according to the equation shown in Figure 4C. C, Steady-state voltage dependence of inactivation for each cell. Cells were prepulsed for $200 \mathrm{msec}$ at various holding potentials (from -120 to $20 \mathrm{mV}$ in 10 $\mathrm{mV}$ increments), and then $\mathrm{Na}^{+}$current was evoked by a step depolarization to $-10 \mathrm{mV}$. Solid lines were fitted by the equation shown in Figure 4C. D, Recovery from the inactivated state. Recovery ratios from the inactivated state $\left(I / I_{\max }\right)$ were measured for various interpulse intervals. The curves were fitted using a Boltzmann function as described above. Each point is given as mean \pm SEM. The standard curves for WT shown in Figure 4 were overlaid on all figures as a dotted line.

GEFS+, a rather benign idiopathic epilepsy, the SCN1A mutations were exclusively of the missense type (Escayg et al., 2000, 2001; Sugawara et al., 2001a; Wallace et al., 2001b). By contrast, in SMEI, a severe and intractable epilepsy, most of them were nonsense or frameshift mutations (Claes et al., 2001; Sugawara et al., 2002). As for SCN2A, we previously described one missense mutation in a family diagnosed with febrile and afebrile seizures (Sugawara et al., 2001b), and a recent report documented two missense mutations of SCN2A in patients with benign familial neonatal-infantile seizures (Heron et al., 2002). Here we identified the first nonsense mutation of SCN2A in a patient with intractable epilepsy and severe mental deterioration. Thus, for both SCN1A and SCN2A voltage-gated sodium channels, missense mutations tend to result in benign idiopathic epilepsy, whereas truncation mutations lead to severe and intractable epilepsy, suggesting a similar underlying mechanism for disease.

Various functional effects of the GEFS + mutations in SCN1A have been suggested (Alekov et al., 2001; Spampanato et al., 2001; Lossin et al., 2002, 2003). For the SCN1B mutation, co expression of the $\beta 1$ subunit harboring the GEFS + mutation with the $\alpha$ subunit showed slowed inactivation, suggesting an increment of $\mathrm{Na}^{+}$currents in patients (Wallace et al., 1998). For the GEFS+ mutation of SCN2A, we demonstrated that the mutant channel inactivated more slowly than wild type and proposed that the augmentation of $\mathrm{Na}^{+}$currents could lead to neuronal hyperex- citability (Sugawara et al., 2001b). In contrast to GEFS+, a preponderance of SMEI mutations are truncation mutations (Claes et al., 2001; Ohmori et al., 2002; Sugawara et al., 2002), indicating that a decrease, rather than an increase, of $\mathrm{Na}^{+}$currents may generate the SMEI phenotype. We recently described attenuated $\mathrm{Na}^{+}$currents of Nav1.1 with SMEI mutations (Sugawara et al., 2003).

For the molecular pathology of our SCN2A-R102X case, one of the possible explanations is haploinsufficiency caused by, for example, nonsense-mediated mRNA decay (Chang and Kan, 1979; Hentze and Kulozik, 1999). However, the heterozygous SCN2A knock-out mouse $\left(\mathrm{Na}_{\mathrm{v}} 1.2^{+/-}\right)$that we generated previously showed no neuroanatomical abnormalities, no significant behavioral abnormalities, and no convulsive seizures (PlanellsCases et al., 2000). Heterozygosity of the nonsense mutation in the SCN2A gene may not have equivalent consequences in mouse as in human, but the findings in mice raise the alternative possibility that the truncated protein caused by R102X mutation is actually produced and exerts a dominant negative effect on the function of the remaining wild-type $\mathrm{Na}_{\mathrm{v}} 1.2$ channels.

Our patch-clamp analysis indeed revealed a dominantnegative effect of the R102X mutant on the WT $\mathrm{Na}_{\mathrm{v}} 1.2$ protein. The hyperpolarizing shift of the inactivation curve in cells coexpressing the WT channel and R102X protein (Fig. 4C,D) is consistent with the decrease of available channels (Hille, 2001). As summarized in Figure $4 C, \sim 80 \%$ of the $\mathrm{Na}_{\mathrm{v}} 1.2$ channel would be in the inactivated state at the physiological potential (at -70 $\mathrm{mV}$ ), and no $\mathrm{Na}^{+}$current would be evoked at the threshold potential of approximately $-50 \mathrm{mV}$. These data suggest that the heterozygous R102X mutation affected the hypoexcitability of $\mathrm{Na}^{+}$channels and would lead to a further attenuation of $\mathrm{Na}^{+}$ currents than alternative simple haploinsufficiency cases. Recently, a heterozygous nonsense mutation of the voltage-gated $\mathrm{P} / \mathrm{Q}$-type calcium channel gene CACNA1A was reported in a patient with a complex phenotype comprising epilepsy, ataxia, and learning difficulties (Jouvenceau et al., 2001). The patchclamp analysis demonstrated a dominant negative effect of the mutant channel in cotransfection with WT and a mutant cDNA with the truncation mutation, which by itself is practically nonfunctional, that resulted in drastically reduced calcium currents relative to transfection with WT channel alone (Jouvenceau et al., 2001). Those authors argued that the dominant-negative effect of the mutant calcium channel reflects a disturbance of surface expression of the channel, and such a mechanism may also be applicable to our case.

In the cells coexpressing WT and R102X tagged with Flag at N and $\mathrm{C}$ termini, surprisingly, the inactivation curve of $\mathrm{WT}+\mathrm{R} 102 \mathrm{X}-\mathrm{FlagN}$ overlapped with that of $\mathrm{WT}$, whereas the curve for WT+R102X-FlagC negatively shifted and overlapped with the curve for WT+R102X (Fig. 4C,D). The mechanism of the dominant negative effect for the R102X protein is unknown, but it is of interest that the R102X is an N-terminal tail protein, and the N-terminal tail structure is not equivalent in R102XFlagN but is retained in R102X-FlagC (Fig. 3). These results raise the possibility that the N-terminal tail structure of the $\mathrm{Na}_{\mathrm{v}} 1.2$ channel may interact with key intracellular entities that modulate the voltage dependence of inactivation, and R102X and R102XFlagC interfere with such interactions. We demonstrated that wild-type $\mathrm{Na}_{\mathrm{v}} 1.2$ was essentially localized in the membrane fraction, whereas the R102X-FlagC protein was localized in the cytoplasmic fraction (Fig. 5C). However, R102X is not likely be entirely soluble in the cytosol. The immunofluorescent staining showed that R102X-FlagC was not entirely diffuse, yet it dis- 
played discretely dense foci and a cytoskeletal filament-like structure (Fig. 6, arrowheads). These results raise the possibility that there are some direct or indirect interactions between cytoskeletal filaments with the N-terminal tail of $\mathrm{Na}_{\mathrm{v}} 1.2$, and the truncated mutant R102X may interfere with the physiological binding of $\mathrm{Na}_{\mathrm{v}} 1.2$. For example, ankyrin, which is a family of ubiquitous adapter proteins linking membrane proteins to the spectrin-actin cytoskeleton, is a well known major interacting protein of $\mathrm{Na}_{\mathrm{v}} 1.2$ (Jenkins and Bennett, 2002; Boiko et al., 2003). For $\mathrm{Na}_{\mathrm{v}} 1.2$, the intracellular linker between domains I and II together with the $\mathrm{N}$-terminal region has been proposed as a major interaction site for ankyrin (Bouzidi et al., 2002). Furthermore, the cytoskeleton has been known to modulate sodium channel gating (Matsumoto and Sakai, 1979a,b; Fukuda et al., 1981). Undrovianas et al. (1995) and Maltsev and Undrovinas (1997) demonstrated that cytoskeleton disruption and antibodies to essential proteins of the cytoskeleton such as F-actin, $\beta$-spectrin, and ankyrin alter the voltage dependence and gating kinetics of sodium channels, inducing a second open state and causing prolonged bursts of openings. The R102X may interact with cytoskeletal filaments and modulate the voltage dependence of WT $\mathrm{Na}_{\mathrm{v}} 1.2$.

Our additional patch-clamp experiments showed that the hyperpolarizing shift of the inactivation curve observed in cells expressing the WT channel and R102X protein shown in Figure 4 was not present in cells coexpressing $\beta 1$ and $\beta 2$ subunits (Fig. 7). This indicates that the dominant negative effect of $\mathrm{R} 102 \mathrm{X}$ protein on the $\alpha$ subunit of the sodium channel shown in Figure 4 is masked by $\beta 1$ and $\beta 2$ subunits presumably because of the accelerating effect of the $\beta 1$ subunit on the activation and inactivation kinetics of the channel (Isom et al., 1992). Recently, novel accessory subunits $\beta 3$ (Morgan et al., 2000), which is homologous to $\beta 1$, and $\beta 4$ (Yu et al., 2003), which is homologous to $\beta 2$, were identified in brain. $\mathrm{Na}_{\mathrm{v}} 1.2$ and each $\beta$ subunit individually display distinct distribution patterns and developmental changes of expression level in brain. Thus, the $\mathrm{Na}_{\mathrm{v}} 1.2$ sodium channel complex may not be necessarily composed of $\mathrm{Na}_{\mathrm{v}} 1.2+\beta 1+\beta 2$ subunits in all neurons in brain, but it may assemble with other subunit combinations such as $\mathrm{Na}_{\mathrm{v}} 1.2+\beta 3+\beta 4$ or even only $\mathrm{Na}_{\mathrm{v}} 1.2$ in some neurons or at specific developmental stages. The dominant negative effect of R102X in neurons that have low or no $\beta 1$ and $\beta 2$ subunits may play a role in the pathogenesis of epilepsy and mental decline in this patient with an SCN2A-R102X mutation.

The patient with an SCN2A-R102X mutation presents clinical differences when compared with SMEI patients: (1) this patient develops partial epilepsy, whereas SMEI patients show both features of partial and generalized epilepsies; (2) the patient showed delayed onset (1 year 7 months) and an episode of remission, yet the severity of epilepsy in a later stage ( $>10$ years) is almost identical to that of SMEI; and (3) the patient does not show the temperature sensitivity that affects most SMEI patients. The $\mathrm{Na}_{\mathrm{v}} 1.1$ channel protein encoded by SCN1A is located at the soma of neurons, whereas the $\mathrm{Na}_{\mathrm{v}} 1.2$ protein coded by $S C N 2 A$ is present in axons; furthermore, the tissue distributions of these channels appear to be complementary (Gong et al., 1999). The question of whether the phenotypic difference of theses patients depends on the different expression patterns of sodium channel subtypes, types of mutations, or both awaits further studies. The patient's mother showed febrile seizures, raising the possibility that genetic factors derived from the mother modified the phenotype of the proband. However, we did not identify any mutations in SCN1A, SCN1B, and GABRG2 that are known to be responsible for SMEI, GEFS+, or both and it suggested that the de novo mutation $\mathrm{R} 102 \mathrm{X}$ is the main factor underlying this intractable epilepsy.

In summary, we identified a nonsense mutation of $S C N 2 A$ in a patient with intractable epilepsy and demonstrated a dominant negative effect of the truncated mutant protein on the function of the wild-type human brain $\mathrm{Na}_{\mathrm{v}} 1.2$ channel. These results would pave the way toward an understanding of sodium channel dysfunctions and their involvement in the molecular etiology of epilepsy.

\section{References}

Ahmed CM, Ware DH, Lee SC, Patten CD, Ferrer-Montiel AV, Schinder AF, McPherson JD, Wagner-McPherson CB, Wasmuth JJ, Evans GA, Montal M (1992) Primary structure, chromosomal localization, and functional expression of a voltage-gated sodium channel from human brain. Proc Natl Acad Sci USA 89:8220-8224.

Akai J, Makita N, Sakurada H, Shirai N, Ueda K, Kitabatake A, Nakazawa K, Kimura A, Hiraoka M (2000) A novel SCN5A mutation associated with idiopathic ventricular fibrillation without typical ECG findings of Brugada syndrome. FEBS Lett 479:29-34.

Alekov AK, Rahman MM, Mitrovic N, Lehmann-Horn F, Lerche H (2001) Enhanced inactivation and acceleration of activation of the sodium channel associated with epilepsy in man. Eur J Neurosci 13:2171-2176.

Baulac S, Gourfinkel-An I, Picard F, Rosenberg-Bourgin M, Prud'homme JF, Baulac M, Brice A, LeGuern E (1999) A second locus for familial generalized epilepsy with febrile seizures plus maps to chromosome 2q21-q33. Am J Hum Genet 65:1078-1085.

Baulac S, Huberfeld G, Gourfinkel-An I, Mitropoulou G, Beranger A, Prud'homme JF, Baulac M, Brice A, Bruzzone R, LeGuern E (2001) First genetic evidence of GABA(A) receptor dysfunction in epilepsy: a mutation in the gamma2-subunit gene. Nat Genet 28:46-48.

Boiko T, Van Wart A, Caldwell JH, Levinson SR, Trimmer JS, Matthews G (2003) Functional specialization of the axon initial segment by isoformspecific sodium channel targeting. J Neurosci 23:2306-2313.

Bouzidi M, Tricaud N, Giraud P, Kordeli E, Caillol G, Deleuze C, Couraud F, Alcaraz G (2002) Interaction of the Nav1.2a subunit of the voltagedependent sodium channel with nodal ankyrin G: in vitro mapping of the interacting domains and association in synaptosomes. J Biol Chem 277:28996-29004.

Chang JC, Kan YW (1979) beta 0 thalassemia, a nonsense mutation in man. Proc Natl Acad Sci USA 76:2886-2889.

Claes L, Del-Favero J, Ceulemans B, Lagae L, Van Broeckhoven C, De Jonghe P (2001) De novo mutations in the sodium-channel gene SCN1A cause severe myoclonic epilepsy of infancy. Am J Hum Genet 68:1327-1332.

Dravet C (1978) Les épilepsie grave de l'enfant. Vie Med 8:543-548.

Dravet C, Roger J, Bureau M, Bernardina BD (1982) Myoclonic epilepsies in childhood. In: Advances in epileptology (Akimoto H, Seino M, Ward A, eds), pp 135-140. New York: Raven.

Dravet C, Bureau M, Guerrini R, Giraud N, Toger J (1992) Severe myoclonic epilepsy in infants. In: Epileptic syndromes in infancy, childhood and adolescence, Ed 2 (Roger JBM, Dravet Ch, Dreifuss FE, Perret A, Wolf P, eds), pp 75-88. London: Libbey.

Escayg A, Heils A, MacDonald BT, Haug K, Sander T, Meisler MH (2001) A novel SCN1A mutation associated with generalized epilepsy with febrile seizures plus-and prevalence of variants in patients with epilepsy. Am J Hum Genet 68:866-873.

Escayg A, MacDonald BT, Meisler MH, Baulac S, Huberfeld G, AnGourfinkel I, Brice A, LeGuern E, Moulard B, Chaigne D, Buresi C, Malafosse A (2000) Mutations of SCN1A, encoding a neuronal sodium channel, in two families with GEFS+2. Nat Genet 24:343-345.

Fujiwara T, Sugawara T, Mazaki-Miyazaki E, Takahashi Y, Fukushima K, Watanabe M, Hara K, Morikawa T, Yagi K, Yamakawa K, Inoue Y (2003) Mutations of sodium channel alpha subunit type 1 (SCN1A) in intractable childhood epilepsies with frequent generalized tonic-clonic seizures. Brain 126:531-546.

Fukuda J, Kameyama M, Yamaguchi K (1981) Breakdown of cytoskeletal filaments selectively reduces $\mathrm{Na}$ and $\mathrm{Ca}$ spikes in cultured mammal neurones. Nature 294:82-85.

Gong B, Rhodes KJ, Bekele-Arcuri Z, Trimmer JS (1999) Type I and type II $\mathrm{Na}(+)$ channel alpha-subunit polypeptides exhibit distinct spatial and 
temporal patterning, and association with auxiliary subunits in rat brain. J Comp Neurol 412:342-352.

Harkin LA, Bowser DN, Dibbens LM, Singh R, Phillips F, Wallace RH, Richards MC, Williams DA, Mulley JC, Berkovic SF, Scheffer IE, Petrou S (2002) Truncation of the GABA(A)-receptor gamma 2 subunit in a family with generalized epilepsy with febrile seizures plus. Am J Hum Genet 70:530-536.

Hentze MW, Kulozik AE (1999) A perfect message: RNA surveillance and nonsense-mediated decay. Cell 96:307-310.

Heron S, Crossland K, Andermann E, Phillips H, Hall A, Bleasel A, Shevell M, Mercho S, Seni M, Guiot M, Mulley J, Berkovic S, Scheffer I (2002) Sodium-channel defects in benign familial neonatal-infantile seizures. Lancet 360:851.

Hille B (2001) Ion channels of excitable membrane, Ed 3. Sunderland, MA: Sinauer.

Isom LL, De Jongh KS, Patton DE, Reber BF, Offord J, Charbonneau H, Walsh K, Goldin AL, Catterall WA (1992) Primary structure and functional expression of the $\beta 1$ subunit of the rat brain sodium channel. Science 256:839-842.

Ito M, Nagafuji H, Okazawa H, Yamakawa K, Sugawara T, Mazaki-Miyazaki E, Hirose S, Fukuma G, Mitsudome A, Wada K, Kaneko S (2002) Autosomal dominant epilepsy with febrile seizures plus with missense mutations of the $(\mathrm{Na}+)$-channel alpha 1 subunit gene, SCN1A. Epilepsy Res 48:15-23.

Jenkins SM, Bennett V (2002) Developing nodes of Ranvier are defined by ankyrin-G clustering and are independent of paranodal axoglial adhesion. Proc Natl Acad Sci USA 99:2303-2308.

Jouvenceau A, Eunson LH, Spauschus A, Ramesh V, Zuberi SM, Kullmann DM, Hanna MG (2001) Human epilepsy associated with dysfunction of the brain P/Q-type calcium channel. Lancet 358:801-807.

Lossin C, Wang DW, Rhodes TH, Vanoye CG, George Jr AL (2002) Molecular basis of an inherited epilepsy. Neuron 34:877-884.

Lossin C, Rhodes TH, Desai RR, Vanoye CG, Wang D, Carniciu S, Devinsky O, George Jr AL (2003) Epilepsy-associated dysfunction in the voltagegated neuronal sodium channel SCN1A. J Neurosci 23:11289-11295.

Maltsev VA, Undrovinas AI (1997) Cytoskeleton modulates coupling between availability and activation of cardiac sodium channel. Am J Physiol 273:H1832-H1840.

Matsumoto G, Sakai H (1979a) Microtubules inside the plasma membrane of squid giant axons and their possible physiological function. J Membr Biol 50:1-14.

Matsumoto G, Sakai H (1979b) Restoration of membrane excitability of squid giant axons by reagents activating tyrosine-tubulin ligase. J Membr Biol 50:15-22.

Morgan K, Stevens EB, Shah B, Cox PJ, Dixon AK, Lee K, Pinnock RD, Hughes J, Richardson PJ, Mizuguchi K, Jackson AP (2000) beta 3: an additional auxiliary subunit of the voltage-sensitive sodium channel that modulates channel gating with distinct kinetics. Proc Natl Acad Sci USA 97:2308-2313.

Moulard B, Guipponi M, Chaigne D, Mouthon D, Buresi C, Malafosse A (1999) Identification of a new locus for generalized epilepsy with febrile seizures plus (GEFS+) on chromosome 2q24-q33. Am J Hum Genet 65:1396-1400.
Ohmori I, Ouchida M, Ohtsuka Y, Oka E, Shimizu K (2002) Significant correlation of the SCN1A mutations and severe myoclonic epilepsy in infancy. Biochem Biophys Res Commun 295:17-23.

Planells-Cases R, Caprini M, Zhang J, Rockenstein EM, Rivera RR, Murre C, Masliah E, Montal M (2000) Neuronal death and perinatal lethality in voltage-gated sodium channel alpha(II)-deficient mice. Biophys J 78:2878-2891.

Scheffer IE, Berkovic SF (1997) Generalized epilepsy with febrile seizures plus: a genetic disorder with heterogeneous clinical phenotypes. Brain 120:479-490.

Spampanato J, Escayg A, Meisler MH, Goldin AL (2001) Functional effects of two voltage-gated sodium channel mutations that cause generalized epilepsy with febrile seizures plus type 2. J Neurosci 21:7481-7490.

Sugawara T, Mazaki-Miyazaki E, Ito M, Nagafuji H, Fukuma G, Mitsudome A, Wada K, Kaneko S, Hirose S, Yamakawa K (2001a) Nav1.1 mutations cause febrile seizures associated with afebrile partial seizures. Neurology 57:703-705.

Sugawara T, Tsurubuchi Y, Agarwala KL, Ito M, Fukuma G, Mazaki-Miyazaki E, Nagafuji H, Noda M, Imoto K, Wada K, Mitsudome A, Kaneko S, Montal M, Nagata K, Hirose S, Yamakawa K (2001b) A missense mutation of the $\mathrm{Na}+$ channel alpha II subunit gene $\mathrm{Na}(\mathrm{v}) 1.2$ in a patient with febrile and afebrile seizures causes channel dysfunction. Proc Natl Acad Sci USA 98:6384-6389.

Sugawara T, Mazaki-Miyazaki E, Fukushima K, Shimomura J, Fujiwara T, Hamano S, Inoue Y, Yamakawa K (2002) Frequent mutations of SCN1A in severe myoclonic epilepsy in infancy. Neurology 58:1122-1124.

Sugawara T, Tsurubuchi Y, Fujiwara T, Mazaki-Miyazaki E, Nagata K, Montal M, Inoue Y, Yamakawa K (2003) Nav1.1 sodium channels with mutations of severe myoclonic epilepsy display attenuated currents. Epilepsy Res 54:201-207.

Undrovinas AI, Shander GS, Makielski JC (1995) Cytoskeleton modulates gating of voltage-dependent sodium channel in heart. Am J Physiol 269:H203-H214.

Wallace RH, Wang DW, Singh R, Scheffer IE, George Jr AL, Phillips HA, Saar K, Reis A, Johnson EW, Sutherland GR, Berkovic SF, Mulley JC (1998) Febrile seizures and generalized epilepsy associated with a mutation in the $\mathrm{Na}+$-channel beta 1 subunit gene SCN1B. Nat Genet 19:366-370.

Wallace RH, Marini C, Petrou S, Harkin LA, Bowser DN, Panchal RG, Williams DA, Sutherland GR, Mulley JC, Scheffer IE, Berkovic SF (2001a) Mutant GABA(A) receptor gamma2-subunit in childhood absence epilepsy and febrile seizures. Nat Genet 28:49-52.

Wallace RH, Scheffer IE, Barnett S, Richards M, Dibbens L, Desai RR, Lerman-Sagie T, Lev D, Mazarib A, Brand N, Ben-Zeev B, Goikhman I, Singh R, Kremmidiotis G, Gardner A, Sutherland GR, George Jr AL, Mulley JC, Berkovic SF (2001b) Neuronal sodium-channel alpha1subunit mutations in generalized epilepsy with febrile seizures plus. Am J Hum Genet 68:859-865.

Yu FH, Westenbroek RE, Silos-Santiago I, McCormick KA, Lawson D, Ge P, Ferriera H, Lilly J, DiStefano PS, Catterall WA, Scheuer T, Curtis R (2003) Sodium channel beta4, a new disulfide-linked auxiliary subunit with similarity to $\beta 2$. J Neurosci 23:7577-7585. 